\title{
Perceived Barriers to Workforce Training: Views from Job Seekers, Employers and Community Colleges in Missouri, USA
}

\author{
Ong Wei Jun Dan \\ Department of Respiratory Therapy \\ Jurong Health Campus, National University Health System \\ 1 Jurong East Street 21, Singapore 609606, Singapore \\ Pat Curry \\ ExCEED \\ University of Missouri Extension \\ Missouri, USA \\ David O'Brien \\ Rural Soiology \\ University of Missouri-Columbia \\ Missouri, USA
}

\begin{abstract}
Purpose: The research reported in this study addresses questions central to improving access to job training at the community level. The differentiation in barriers to accessing workforce training within the same OMB classification counties emphasizes the need to place the challenge of accessing workforce training within a broader "total systems" approach to community economic development in terms of building network linkages between the stakeholders, within the specific constraints and opportunities offered by each individual place. The surveys of the community college and employers were conducted between March and May 2018. The surveys of job seekers were conducted between March 2018 and January 2019 at the State Employment Centers when job seekers came in for services. It is important to understand how ultimately the success or failure to achieve cooperation between employer and the job seekers may require active participation in the political processes at both the state and federal levels.
\end{abstract}

Keyword: Barriers Faced by Job seekers; OMB classification; Community Economic Development; State Employment Centers; Community College; Employers.

\section{Introduction}

One of the major challenges to building and maintaining sustainable communities at all levels, is to find ways to enhance the training of the workforce for $21^{\text {st }}$ Century jobs. This is especially the case in rural regions that have suffered a decline in jobs in manufacturing and agriculture. There is a growing public consensus of the need to devote more material resources to accomplishing this goal. A substantial challenge remains, however, in identifying precisely what are the obstacles to linking working age persons to training that will improve their economic livelihood, and, in turn, their mental and physical health, as well as provide a significant boost to local, state and national economies (Melloy, Liu, Grandey, \& Shi, 2018). In addition to the taxpayers, there are three key stakeholders on this topic: employers who need more highly trained workers; community colleges whose mission includes offering specific job training programs; and workers who either are currently unemployed or seeking to improve their skills in order to get better jobs. The first challenge, then, is to identify what is the degree of alignment of the perceptions of obstacles to training by job seekers, employers and community colleges. The second is, to identify to what extent are job seekers' perceptions of obstacles to training associated with the demographic and economic conditions of the community in which they live; specifically, what they are the specific obstacles to job training that are associated with different degrees of rural versus metropolitan location Overall, the literature on barriers to accessing job training describes three basic types of obstacles: lack of availability of training that is connected to jobs that individuals can access within a reasonable commuting distance of where they live; inadequate infrastructure to support $21^{\text {st }}$ Century jobs in the communities where job seekers live; and the personal characteristics of potential job trainees. Each of these receives greater or lesser attention by different stakeholders as well as being more or less important depending on where the training will take place and where the potential trainee lives. 
Intuitively, we would expect that potential trainees would be most concerned about the availability of training in locations that they can conveniently access. However, a significant challenge here is matching specific types of training with specific job opportunities that either currently exist or that could be developed as part of a master plan for community or regional economic development. Different areas within the same state present different opportunities and challenges. There are both economic and demographic factors that make specific places within the same state more or less attractive to potential employers, and, in turn, provide an environment for greater or lesser support for programs to provide trained workers for available or potential jobs. Central issues here are access to supply chains, labor costs, and other traditional economic factors as well as area-specific demographic characteristics, such as the age and education of the population. The availability of broad band internet connectivity, which is associated with spatial constraints - i.e., market-based services in low density populated areas - is especially important in remote rural areas, where almost onequarter of the population lacks access to it. This is not only relevant to gaining job training skills, that typically involve internet access, but also impacts the health and mental health of the local population (Anderson, 2018). The barriers described so far involve technical solutions, which, of course, involve financial considerations and public taxpayer and employer contributions. A more complex and diverse barrier to accessing job training falls under the general rubric of "personal characteristics" of those who are potential trainees. The following list of seven personal barriers is found in a white paper developed by a company in the business of linking job seekers to jobs and job training: Transportation, Child Care, Elder Care, Job Training, Drug Use and Drug Testing, Criminal Record, and Communication Issues (Express Employment Professionals, 2019). Many of these same barriers exist in European nations.(Altmann, Falk, Jager and Zimmermann, 2018; Tisch, 2015).

Personal characteristics of potential job trainees cover a wide range, that differs markedly between different stakeholder groups. Employers are most likely to cite criminal background, alcohol and drug addiction, and the failure of employees to show up for work on time or who call in sick. Job seekers, on the other hand, are likely to cite personal obstacles like transportation, the cost of child care or the need for a flexible work schedule so that they can take care of home responsibilities. Some state-level job training programs have attempted to address these issues by incorporating mental health and other employee assistance programs into job training and matching jobs to clients. This means integrating treatment for such conditions into an overall plan to improve job training and job access (Acikgoz, 2019;Liu, Huang, \& Wang, 2014;King \& Waghorn 2018; McGee, 2015). A key player in the development of this integrated "systems approach" has been locally-based community colleges. These organizations have the ability to transfer technical skills to students, but most importantly, are embedded in local communities and thus have the ability to link the various stakeholders (Corbin \& Thomas, 2019). A critical challenge for these organizations, as well as state government departments responsible for workforce development, however, is how, precisely, do different stakeholders perceive the barriers to accessing workforce training? This was the central question posed by the team that designed and conducted this project.

\section{Materials and Methods}

\subsection{The State of Missouri, USA as a Setting for Studying Barriers to Workforce Training}

There are two reasons why Missouri is an ideal location for studying barriers to workforce training. First, although having a long tradition of a mixed industrial and agricultural economy, the state has lagged behind others in recovering from the 2008 recession. Second, Missouri contains counties that cover the full range of rural to urban characteristics.

\subsection{Overall Rural versus Metropolitan Population and Economic Trends}

Prior to the 2007 Recession Missouri's population was increasing at a rate well below national average; 2001 and 2007 was $4.4 \%$ from 2001 to 2007 , which ranked 30th in the US. The US rate was $5.7 \%$ during the same period. The population increased in 86 of 115 counties and 34 counties had rates of growth equal to or greater than the US. Only 39 counties have returned to 2007 employment totals and 17 have growth rates greater than the US average. Missouri's employment gains prior to the Recession also were well below the national rate; an increase of 3.2\% (+94,460 jobs) compared with the national growth rate of 5.3\%. Although 79 counties added jobs, only 58 had growth rates equal to the US rate. In the post-recession period the State has experienced very slow employment growth, adding only 79,866 jobs for a $2.6 \%$ growth rate, approximately one-third of the US rate of growth (University of Missouri Extension, 2018). The second feature of the state that is most relevant to this project is the distribution of counties along a rural to urban continuum. This is especially useful in examining the extent to which geo-spatial factors have affected both job and population loss and recovery, as well as, whether these factors are associated with different perceptions of barriers to accessing job training. Figure 1 shows the distribution of counties along the rural to urban continuum developed by the U. S. Office of Management and Budget (Office of Management and Budget, 2018). 
Figure 1: Comparison between the US Office of Management and Budget County Classification and 2018 Composite Resiliency Index for Missouri Counties (OMB, 2018)
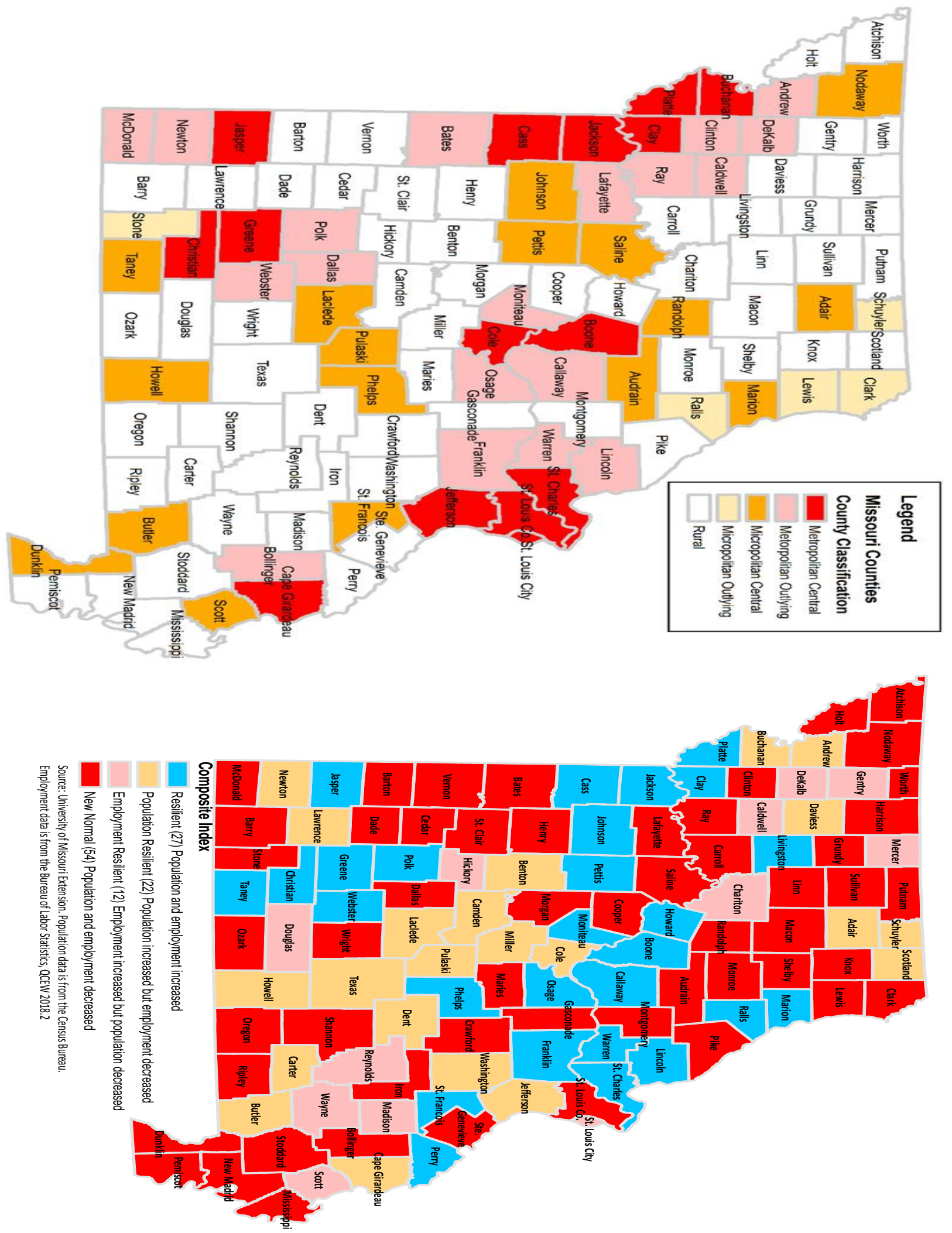

2.3. The Office of Management and Budget (OMB) definitions include:

- Metropolitan (Metro) counties have at least one urbanized place with a population of 50,000 or more. There are 15 Metro counties in Missouri. 
- Metropolitan Outlying (Metro Outlying) counties have at least 25\% of workers employed in a neighboring Metro county. There are 19 Metro Outlying counties in Missouri.

- Micropolitan (Micro)counties have an urbanized area with a population of 10,000 but less than 50,000. There are 17 Micro counties in Missouri.

- Micropolitan Outlying (Micro Outlying) send at least 25\% of workers to a neighboring Micropolitan county. There are 5 Micro Outlying counties in Missouri.

- Rural counties, are the most isolated places and do not have an urbanized area with a population of at least 10,000. There are 59 Rural counties in Missouri. Nearly $80 \%$ of all new jobs are in five Metro counties (St. Charles +27,197, Clay $+17,077$, Boone $+13,803$, Greene $+9,531$, and Platte $+8,412$ ). Rural areas have experienced the slowest recovery with 48 of 59 Rural counties still below 2007 employment levels, with a net job deficit of $-17,945$ [16]. Two-thirds (19) of the 29 counties that lost population were Rural. Between 2007 and 2017 the state's population increased by only $3.8 \%(+225,920)$ which ranked $37^{\text {th }}$ among the states in the US growth rate (Office of Management and Budget, 2018).

\subsection{The Missouri Population and Employment Composite Index}

To obtain a more precise view of differences between counties in their ability to recover from the 2008 recession, the University of Missouri Extension has created a Composite Index, that includes both population and employment trends. The population indicator is compiled from the Census Bureau's population estimates program. The employment indicator includes only full-time employment and is sourced from EMSI's tabulations of the Bureau of Labor Statistics Quarterly Census of Employment and Wages (University of Missouri Extension, 2018). This paper uses the 2017 population data and employment tabulations from the second quarter of the 2018 Quarterly Census of Employment and Wages. The Composite Index is calculated by summing the percent change in population and the percent change in employment from a base year of 2007. Counties are assigned to one of four categories based on the growth in population and employment. The categories are:

- Resilient counties that have returned to, or have exceeded, 2007 population and employment.

- Population Resilient counties that have recovered to 2007 population but not employment.

- Employment Resilient counties that have recovered to 2007 employment but not population.

- New Normal - counties that have not returned to 2007 employment or population benchmarks.

2.5. Current Statistics from the Composite Index in Missouri

The composite index categories for each Missouri county are shown in Figure 1.Resilient Counties - As of August 2018 there were only 27 counties that have recovered to 2007 population and employment levels, 17 of which are metropolitan regions. Population increased by 237,998 and employment increased by 94,325 in these counties but growth was highly concentrated in the urban counties where $85.8 \%(+204,298)$ of population and $88.2 \%(+83,199)$ of employment growth occurred. The combined totals for St. Charles (west of St. Louis) and Clay (north east of Kansas City) counties comprised $34.3 \%(+81,804)$ of all population growth and $46.9 \%(+44,274)$ of employment gains. Population Resilient Counties - There are 22 counties in the Population Resilient category which is dominated by 10 Rural counties. Pulaski (9.9\%), located in the heart of the Ozarks but including a U. S. Army Facility Fort Leonard Wood, was the only county with growth above the national rate of $8.1 \%$. The total population increase for all counties in this category was 29,997. This group of counties, however, had an employment deficit of -18,204. Employment Resilient Counties- There are only 12 counties in this category, 8 of which are Rural counties. As a group these counties only added 3,499 jobs and experienced total population losses of -12,492. New Normal - There are 54 counties that have not returned to 2007 population or employment levels. There are 38 Rural counties in this group. Their total population loss is $-29,583$ and their employment deficit is $-26,214$. Combined deficits of greater than $-10 \%$ are found in 32 of the 54 counties in this category.

2.6. The Sample Frame, Sample Selection and Administration of the Surveys

The sample frames for the three stakeholder groups were developed in the following manner. The Missouri Community College Association provided an email list of individuals in each of the 12 community colleges who were "liaisons" to employers. These individuals worked with employers to synchronize community college training programs with employer needs. The employer sample frame was a list of employers with whom the community colleges worked on a regular basis. The sample frame for the job seekers was comprised of individuals who sought assistance from the employment centers throughout the state of Missouri, oftentimes to find a path to additional training and better jobs. The on-line Qualtrics program was used to administer the surveys to all three groups. The job seekers filled their survey out at the job center. Table 1 shows the demographic and locational profile of the job seekers' sample. 
Table 1. Demographic and Locational Profile of the Job Seekers Sample (N=688)

\begin{tabular}{ll}
\hline $\begin{array}{l}\text { Personal Characteristics } \\
\text { Age }\end{array}$ & \multicolumn{1}{c}{ Count(\%) } \\
$18-24$ & $63(9.2 \%)$ \\
$25-34$ & $154(22.4 \%)$ \\
$35-44$ & $151(21.9 \%)$ \\
$45-54$ & $157(22.8 \%)$ \\
$55-64$ & $131(19.2 \%)$ \\
$65+$ & $32(4.7 \%)$ \\
Gender & \\
Male & $288(42.4 \%)$ \\
Education & \\
Below High School & $42(6.1 \%)$ \\
High School Graduate & $195(28.4 \%)$ \\
Some College & $221(32.2 \%)$ \\
Associate Degree & $74(10.8 \%)$ \\
Bachelor's degree & $103(15.0 \%)$ \\
Graduate Degree & $6(0.9 \%)$ \\
Income & \\
Less than \$40,000 & \\
\$40,000 to \$79,000 & $425(63.6 \%)$ \\
Above \$80,000 & $154(25.7 \%)$ \\
Community & $73(10.8 \%)$ \\
Resilient & \\
Employment Resilient & \\
Population Resilient & $31(4.5 \%)$ \\
New Normal & $62(9.1 \%)$ \\
\hline
\end{tabular}

The only statistically significant difference in the personal characteristics of the job seekers sample is that those from the resilient places are more likely to have an associate degree or higher $(35.6 \%)$ than those living in the new normal places $(26.1 \%)(\mathrm{p}<.001)$. Table 2 shows the distribution of the employers and community college samples by type of county in which they work. Approximately one-third of the employer sample and almost one-half of the community college liaison sample did not answer the question on their work location. 
Table 2. Location of Employer and Community College Respondents

\begin{tabular}{ccc} 
Community Type & $\begin{array}{c}\text { Employers } \\
(\mathrm{n}=87)\end{array}$ & $\begin{array}{c}\text { Community Colleges } \\
(\mathrm{n}=30)\end{array}$ \\
\hline Resilient & $32(36.8 \%)$ & $6(20 . \%)$ \\
Employment Resilient & $3(3.4 \%)$ & $1(3.0 \%)$ \\
Population Resilient & $15(17.2 \%)$ & $3(10.0 \%)$ \\
New Normal & $8(9.2 \%)$ & $7(23.3 \%)$
\end{tabular}

\begin{tabular}{|l|l|}
\hline \multicolumn{2}{|c|}{ Table 3a. Job Seekers' Top 8 Obstacles to Job Training and Percentage of those Rating above 3} \\
(N=684) \\
\hline Lack of jobs in my Area & $67.0 \%$ \\
\hline Lack of financial Support & $60.3 \%$ \\
\hline Lack of specialized job training & $55.5 \%$ \\
\hline Lack of vocational training & $49.6 \%$ \\
\hline Lack of information in job training & $49.0 \%$ \\
\hline Commuting distance & $43.6 \%$ \\
\hline Lack of access to high speed broadband & $30.9 \%$ \\
\hline \multicolumn{2}{|l|}{ Table 3b. Employers' Top 8 Obstacles to Job Training and Percentage of those Rating above 3 (N=87) } \\
\hline Lack of specialized Job Training & $68.3 \%$ \\
\hline Vocational training fit jobs in my area & $61.7 \%$ \\
\hline Lack of affordable childcare & $58.3 \%$ \\
\hline Criminal record & $56.1 \%$ \\
\hline Lack of financial support & $56.0 \%$ \\
\hline Lack of information in job training & $54.9 \%$ \\
\hline Drug/alcohol addiction & $54.4 \%$ \\
\hline Commuting distance & $53.1 \%$ \\
\hline \multicolumn{1}{|c|}{ No Location Given } & $29(33.3 \%)$ \\
\hline
\end{tabular}

\section{Results}

3.1. How Job Seekers, Employers and Community Colleges See Obstacles to Job Training

The survey asked job seekers, employers and community college liaisons to indicate on a scale of 1 to 4 , with 1 being not very important and 4 being very important, how important is each of a list of obstacles to job training that had been reported in the literature. Tables $3 \mathrm{a}, 3 \mathrm{~b}$ and $3 \mathrm{c}$ show the list of the top perceived obstacles by the job seekers, employers and community college liaisons. The numbers shown in these tables are the percent of respondents who gave each obstacle a score of 3 or 4 on a four-point scale.

$\begin{aligned} & \text { Table 3c. Community College Liaisons' Top } 8 \text { Obstacles to Job } \\ & \text { those rating above } \mathbf{3}(\mathbf{N}=\mathbf{2 0})\end{aligned}$
$\begin{array}{ll}\text { Lack of state funding for Community } & \text { Colleges/ } \\ \text { workforce development } & 95.2 \% \\ \text { Lack of transportation } & 57.4 \% \\ \text { Lack of affordable childcare } & 52.4 \% \\ \text { Lack of information on job training } & 42.9 \% \\ \text { Commuting distance } & 42.9 \% \\ \text { Lack of specialized job training } & 38.1 \% \\ \text { Criminal record } & 33.4 \% \\ \text { Lack of access to high speed broadband } & 33.3 \%\end{array}$

There are important differences between these three groups on several dimensions. Job seekers listed lack of jobs in my area as their number one concern, while it was not even in the top eight in the employers' list. Employers listed affordable childcare as their third most important concern, while job seekers ranked this eighth. 
Employers included criminal record and drug/alcohol abuse among their top eight, while job seekers did not list these concerns in their list of top eight obstacles. The community college representatives rated "lack of state funding for colleges and workforce development" as their top concern.

3.2. How Specific Obstacles to Job Training are Related to One Another

To obtain a clearer picture of how specific obstacles to job training might be connected to one another, a factor analysis of job seekers' responses to questions about obstacles to job training, using the 1 to 4 scale was conducted. ${ }^{1}$ Items that load on a given factor, .500 or higher, signify that respondents who answered a certain way on that question gave a similar response to other statements that also loaded on that factor. The results are shown in Table 4.

Table 4. Factor Analysis Loadings on Job Seekers' Perceptions of Obstacles to Job Training (Varimax Rotation) $(\mathbf{N}=684)$

Lack of jobs in my area

Lack of information on job training

Lack of specialized job training

Vocational training that fits jobs in my area

Lack of access to internet/broadband

Lack of access to cellular service

Lack of financial support

Lack of transportation

Commuting distance

Lack of affordable childcare

Physical disabilities

Mental health

Drug/alcohol addiction

Lack of high school diploma/GED

Criminal record

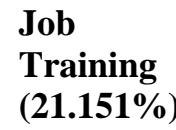

Factor1

.640

.835

.872

.799

.251

.206

.369

.008

.170

.167

.181

.120

.080

.070

.037

\section{Personal \\ (19.085\%)}

Factor 2

.173

.133

.080

.103

.105

.191

.086

.355

.217

.556

.610

.701

.794

.683

.780
Infrastructure

(18.043\%)

Factor 3

.154

.179

.215

.255

.640

.599

.686

.746

.725

.335

.149

.181

.110

.164

.112

Table 4 indicates that there are three distinct factors representing different kinds of barriers faced by job seekers that account for 59 percent of the total variance in responses to all of the barrier items. Each of the three factors accounts for approximately the same amount of variance. The first factor, which accounts for 22 percent of the total explained variance, consists of four of the items that appear to reflect a lack of job training opportunities themselves. This includes: "lack of jobs", "lack of information on job training", "lack of specialized job training" and "insufficient vocational training." The second factor, which accounts for 19 percent of the total variance, is personal obstacles that limit a job seeker's capacity to access training even when it is available. This includes: "lack of affordable childcare," "physical disabilities," "mental health," "drug and/or alcohol addiction," "lack of high school diploma" and "criminal record." The third factor, which accounts for 19 percent of the variance, is lack of infrastructure, which includes: "lack of access to high speed broadband," "lack of access to cellular service," "lack of financial support," "lack of transportation" and "commuting distance."

Figure 2 shows the similarities and differences in the perceptions of job seekers, employers and community college liaisons to the three broad groupings of factors - "job training," "personal" and "infrastructure" that were shown in Table 4. The percentages are based on the number of respondents in each sample - "job seekers," "employers" and "community college liaisons" with a mean of 3 or more on the items which constitute each of the factors. 
Figure 2. Perceptions of Barriers to Accessing Job Training by Job Seekers, Employers, Community College Representatives. (Percentages are Based on the Number of those in Each Sample who had an Average Rating of 3 or higher on the Items in Each Factor)

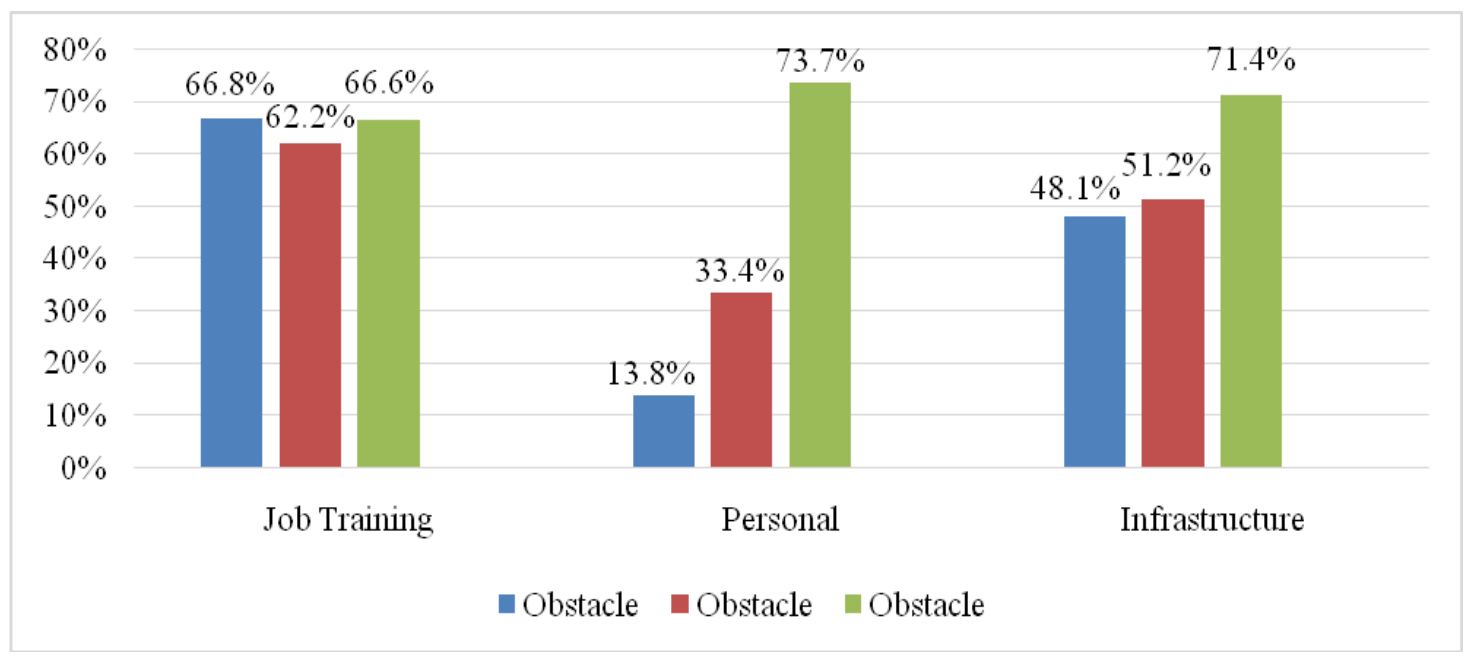

Community college liaisons, which it should be noted is a very small sample, rate all three of the factors as very important, which reflects their experience in dealing with both employers and job seekers. The most interesting finding is the difference between job seekers and employers on personal characteristics. Employers are more than twice as likely as job seekers (33.4\% versus $13.8 \%$ ) to see personal characteristics as a major obstacle to obtaining training to upgrade skills.

\subsection{Rural Versus Urban Effects on Job Seekers' Perceptions of Obstacles}

Tables 5 and 6 provide an overview of the relationship between the job seeker's perceptions of obstacles to accessing job training and whether she or he lives in an urban or rural area.

Table 5. Job Seekers Perceptions of the Importance of the Three Factors as Obstacles to Accessing Job Training in Urban and Rural Counties (Scale - 1-4, with 4 Being a Most Important Obstacle)

\begin{tabular}{lllll} 
& \multicolumn{2}{c}{ Urban(n=545) } & \multicolumn{2}{c}{ Rural(n=139) } \\
Obstacles & Mean & Standard & Mean & Standard \\
& & Deviation & & Deviation \\
Personal & 1.71 & 0.840 & 1.84 & 0.828 \\
Infrastructure*** & 2.43 & 0.935 & 2.73 & 0.866 \\
Job Training*** & 2.82 & 0.986 & 3.11 & 0.914 \\
$* * * p<.001$. & & & &
\end{tabular}

Table 6. Job Seekers Perceptions of Specific Obstacles to Job Training in Urban and Rural Counties (Scale - 14, with 4 Being a Most Important Obstacle)

\begin{tabular}{|c|c|c|c|c|}
\hline \multirow[b]{2}{*}{ Obstacles } & \multicolumn{2}{|c|}{$\operatorname{Urban}(\mathrm{n}=545)$} & \multicolumn{2}{|c|}{$\operatorname{Rural}(\mathrm{n}=139)$} \\
\hline & Mean & $\begin{array}{l}\text { Standard } \\
\text { Deviation }\end{array}$ & Mean & $\begin{array}{l}\text { Standard } \\
\text { Deviation }\end{array}$ \\
\hline Lack of jobs in my Area** & 2.79 & 1.193 & 3.18 & 1.199 \\
\hline Lack of specialized job training* & 2.60 & 1.228 & 2.85 & 1.154 \\
\hline Commuting distance** & 2.22 & 1.218 & 2.70 & 1.289 \\
\hline Lack access to internet/ broadband ${ }^{* *}$ & 1.95 & 1.188 & 2.33 & 1.332 \\
\hline Lack access to cellular services* & 1.63 & 0.979 & 1.83 & 1.063 \\
\hline
\end{tabular}

Tables 5 and 6 collapse the OMB classification into two categories, "urban" which includes both metropolitan and metropolitan fringe counties, and "rural", which includes micropolitan and rural county types. Table 5 shows how urban and rural job seekers perceive the importance of the three general factors that were shown earlier in Table 4. 
Overall, rural job seekers perceive a much greater barrier in infrastructure and job training availability. Table 6 shows within each factor those specific barriers that are seen as more challenging to rural than urban job seekers; "jobs", "job training", commuting distance", "broadband" and, "cellular services." These findings are consistent with the views of social scientists and residents themselves who see these conditions as a structural source the despair in rural areas (Khazan, 2019; Maciag, 2018).

\subsection{County Resiliency and Job Seekers' Perceptions of Obstacles}

Counties with different degrees of "resiliency" view the importance of the three general factors - "job training," "personal," and "infrastructure" - as obstacles to accessing training. There were no statistically significant differences between the responses of job seekers in counties with different levels of resiliency. Looking at responses to specific obstacles within two of the three factors, "infrastructure" and "personal," however, reveals important differences between job seekers in the different types of resiliency areas. This is shown in Table 7.

Table 7. Job Seekers' Perceptions of High Speed Broadband and Affordable Childcare as Obstacles to Job Training in Counties with Different Levels of Resiliency (Scale - 1-4, with 4 being a most important obstacle)

\begin{tabular}{lcc}
\multicolumn{1}{c}{ Obstacles } & Mean & Standard Dev \\
\hline Lack of access to internet/broadband & & \\
Resilient & 2.00 & 1.124 \\
Employment Resilient & 2.03 & 1.303 \\
Population Resilient & $2.45^{\mathrm{a}}$ & 1.554 \\
New Normal & $1.97^{\mathrm{a}}$ & 1.205 \\
Lack of affordable childcare & $1.69^{\mathrm{b}}$ & 1.215 \\
Resilient & $2.65^{\mathrm{b}, \mathrm{c}}$ & 1.624 \\
Employment Resilient & 2.08 & 1.518 \\
Population Resilient & $1.80^{\mathrm{c}}$ & 1.290
\end{tabular}

a: Mean differences between population resilient and new normal - $\mathrm{p}<.05$

b: Mean differences between employment resilient and resilient $-\mathrm{p}<.01$

c: Mean differences between employment resilient and new normal - $\mathrm{p}<.01$

Lack of access to internet/broadband is seen as a larger barrier in "population resilient" than in "new normal" places. Population resilient places - i.e., places that have experienced population growth but remain without growth in employment - includes some rural areas that have been able to attract retirees from metro areas, such as Polaski county in the Ozarks (See Figure 1), but also those who are seeking to set up small businesses, such as small farms, bed and breakfasts or other enterprises but are hampered by a lack of internet connectivity. Alternatively, job seekers in "employment resilient" areas are more likely than job seekers in both "new normal" and "resilient" areas to see "lack of affordable childcare" as a serious obstacle to their access to job training. The lower importance of childcare in the "new normal" counties simply is a reflection of an aging population in dying communities. But, "employment resilient" are as have the potential to attract to younger workers to new jobs, but lack "affordable childcare." Finally, it is important to note that even within the OMB metro area classification there are substantial differences in perceptions of obstacles to job training. Table 8 shows the means for the obstacles of "job training", "criminal record" and "addiction issues" between "resilient" Boone county and "new normal" St. Louis county. On all three of these items, the mean scores are significantly higher in the St. Louis county job seeker sample. The largest municipality in Boone county is Columbia, a politically liberal university town with a growing population and jobs, while St. Louis county lost population and businesses to neighboring St. Charles County. 
Table 8 Job Seekers Perceptions of Obstacles to Job Training in Boone and St. Louis Counties (Scale - 1-4, with 4 being a most important obstacle)

\begin{tabular}{|c|c|c|c|c|}
\hline \multirow[b]{2}{*}{ Obstacles } & \multicolumn{2}{|c|}{$\begin{array}{l}\text { Boone } \\
(n=158)\end{array}$} & \multicolumn{2}{|c|}{$\begin{array}{l}\text { St. Louis } \\
(n=309)\end{array}$} \\
\hline & Mean & $\begin{array}{l}\text { Standard } \\
\text { Deviation }\end{array}$ & Mean & $\begin{array}{l}\text { Standard } \\
\text { Deviation }\end{array}$ \\
\hline Lack of information in job training* & 2.25 & 1.100 & 2.51 & 1.229 \\
\hline Criminal record $* *$ & 1.34 & 0.943 & 1.61 & 1.253 \\
\hline Drug/alcohol addiction** & 1.11 & 0.479 & 1.31 & 0.908 \\
\hline $\mathrm{p}<.05$ & & & & \\
\hline $\mathrm{p}<.01$ & & & & \\
\hline
\end{tabular}

Although in recent years both Boone and St. Louis counties have experienced well-published racial incidents, St. Louis county faces the additional burden of having a proliferation of small municipalities within its boundaries (the City of St. Louis is a separate municipality outside of the county. This has seriously hampered St. Louis County, as well as the City of St. Louis, in developing effective collective responses to job losses in the last half of the $20^{\text {th }}$ and the $21^{\text {st }}$ Centuries. A study by Gordon (2008) shows how the effects of municipal and county boundaries on racial segregation and conflict, as well as the overall inertia it causes in dealing with lack of economic growth and low tax revenues, was facilitated by federal policies in the 1930s and 1940s that exacerbated racial segregation and the inability of African Americans to accumulate capital through home equity.

\section{Discussion}

There are three important policy implications of the findings reported above. The first is the specification of where three critical stakeholders - job seekers, employers and community college representatives - agree and where they differ in their perceptions of barriers to job training. Respondents in all three groups list lack of job training programs at or near the top of their lists. Further down the list of obstacles, however, there are differences between the three samples. Community colleges have the most "wholistic" approach, giving almost equal weight to "job training," "personal" and "infrastructure" factors. Job seekers and employers, however, give less weight to "personal" and "infrastructure" barriers (See Tables 3a, 3b, 3c and Figure 3). Employers list "lack of affordable childcare" as the third highest barrier, while, overall, the job seekers in the survey ranked this obstacle as eighth. This gap may be due in part at least to the nature of job seekers sample; that is, many individuals who have problems obtaining childcare may not be as likely to go to the state employment centers, thus staying out of the workforce entirely. Employers may be especially sensitive to this problem because of losing workers with young children in the past and/or not being able to attract potential employees with dependents. Another disconnect between the job seekers' and the employers' samples is the importance of "criminal record" and "substance abuse" as obstacles to training. The employer sample lists both, but they are not on the job seeker sample's list (see Tables 3a and 3b). The second important policy implication of our findings is the need to address obstacles that are more or less relevant to individual counties. It is not surprising to find lack of infrastructure and lack of available job training to be more prevalent in rural than in metropolitan counties (see Table 5). But, the findings also support the view that even within a specific OMB classification; individual counties have a quite different need, which, in turn, calls for different types of assistance to increase access to job training, as well as overall economic development.

The fact that job seekers in "population resilient" counties, which have gained population but not jobs, rank "lack of access to high speed broadband" as a major obstacle, suggests that among their new residents are those who are eager to obtain job training to upgrade their skills and enter the workforce but are blocked by lack of access to the web. This is especially relevant today when access to high speed broadband makes it possible to work remotely for global companies. Alternatively, job seekers in "employment resilient" counties, which have gained jobs but not population, cite "lack of affordable childcare" as their most pressing obstacle to accessing job training. This seems to reflect the availability of jobs but an inability to obtain one unless they find a suitable place to care for their children while they work or receive training (see Table 8).

Finally, even within the broad category of "metro" counties, that overall have done much better than rural counties in gaining both jobs and population, there are substantial differences in the types of obstacles to accessing job training. Job seekers" much greater perception of "lack of information in job training," "criminal record," and "drug/alcohol addiction" in "new normal" St. Louis County than in "resilient" Boone County may reflect some combination of differences in population and economic growth, as well as cultural differences in employers' attitudes toward job seekers in general or toward specific sub-groups of job seekers (see Table 9). 
This emphasizes the need to address ways to overcome the barriers to collective action that are created by the extreme diffusion of political capital in St. Louis county and its relationship to the city of St. Louis.

There is a great deal of research on why some communities do better than others, even within the same geo-spatial constraints and opportunities. One of the major findings in this regard is that the ability of local leaders to work together over time builds a reservoir of social capital trust that can provide the capacity to cope with unexpected exigencies, such as those associated with the loss of a traditional economic base, such as farming or low skill manufacturing. This has been a major focus of both research and community outreach, especially in rural sociology (Brown \& Schafft, 2019; Flora, Flora \& Gasteyer, 2018; O’Brien, Philips \& Patsiorkovsky, 2005). Thus, a critical task is to identify ways to build social network linkages between these groups. This obviously requires material incentives, but also the learning of "soft skills" that address the challenges of incentivizing individuals and groups with very different preferences to work together for collective efforts in which everyone will benefit. One of the best historical examples in this regard has been the success of American agricultural cooperatives that initially started from the ground up, in the small towns where farmers lived and worked, sent their children to the same schools, often attended the same churches, and interacted on a daily or weekly basis. These organizations have been remarkably resilient in adapting to economic, political and social changes over time.

A key element in this success story has been the ability of cooperatives to gain support within state and federal political systems for their unique form of collective governance and to bring pressure, along with their allies, to modify the formal institutional system regulating the American economy. This included, for example, the Smith-Lever Act of 1914, that established the Cooperative Extension Service, which is connected to the Land Grant Universities and provides technical support for community economic development, especially in rural areas. In 1922, the CapperVolstead Act provided an exemption from anti-trust laws for agricultural cooperatives that permitted farmers to collectively bargain with buyers, suppliers and transporters.

The bargaining power of agricultural cooperatives was enabled through a political process that, in effect, essentially suspended portions of a sacrosanct "free market" system for a specific category of producers. This, in turn, has given their farmer members a disproportionate influence on the American political process, at both the state and federal levels (Cook, 1995; Schneiberg, King,\& Smith, 2008).

This brings us to the third major implication of the findings of this study. Ultimately, the ability of job seekers, employers and community colleges to gain the resources to support a "systems approach" to job training depends on their skill in persuading state- and national-level legislators of its value. This involves work at both the federal and state levels of government. The precise details of how such lobbying efforts can be operationalized are beyond the scope of this paper. Nonetheless, there is solid evidence that new organizational forms, with enabling state and federal legislation can be developed to negotiate compromise solutions to meet the needs of different stakeholder groups. A classic example of this is seen in the evolution of the Tennessee Valley Authority (TVA) from a top-down organizational design to one that eventually incorporated grass roots associations into the organizational structure that reduced local opposition to the project. Selznick (2011) refers to this process as "cooptation," a term that increasingly has taken on negative connotations, but it also has meant that local residents in the communities affected by TVA policy have a formal mechanism within which to promote their interests. The current lack of political clout to persuade legislators to provide adequate resources for job training is evidenced in the state of Missouri, where despite the strong support for this objective by all three stakeholder groups, community colleges have faced elimination of targeted training and workforce development programs; in one case having lost funding for four targeted programs in the last five-years.

Most of the funding for these programs comes from the federal government, but those funds have been eliminated because of flat line funding from the state of Missouri. This highlights the importance of understanding how support for better access to job training fits into the political processes at the local, state and federal levels.

Such an approach requires building social capital at the community level, but also building bridging social and political capital that will provide access to outside material and informational resources.

Acknowledgments: The project was supported by the University of Missouri Division of Applied Social Sciences Graduate Community Survey Class, the Missouri Community College Association and the Missouri Department of Economic Development, Workforce Training Section.

Conflicts of Interest: There are no conflicts of interest connected to this research or this report. 


\section{References}

Acikgoz, Y. (2019). Employee recruitment and job search: Towards a multi-level integration. Human Resource Manager, 29(1): 1-13. https://doi.org/10.1016/j.hrmr.2018.02.009

Altmann, S.; Falk, A.; Jager, S., \&Zimmermann, F. (2018). Learning about job search: A field experiment with job seekers in Germany. Journal of Public Economics, (164): 33-49. https://doi.org/10.1016/j.jpubeco.2018.05.003.

Anderson, M. (2018). About a quarter of rural Americans say access to high-speedinternet is a major problem. Pew Research Center, (September 10). Retreived from: https://www.pewresearch.org/fact-tank/2018/09/10/about-aquarter-of-rural-Americans-say-access-to-high-speed-internet-is-a-major-problem/

Brown, David L. and Kai A. Schafft. (2019). Rural people and communities in the $21^{\text {st }}$ century:Resilience and transformation. $2^{\text {nd }}$ Edition. Cambridge U. K.: Polity Press.

Cook, M. L. (1995). The future of U.S. agricultural cooperatives: A neo-institutional approach, American Journal of Agricultural Economics, 77(5): 1153-59.

Corbin, R. A. \& Thomas, R. (2019). Community colleges as incubators of innovation: Unleashing entrepreneurial opportunities for communities and students. Sterling, VA: Stylus.

Express Employment Professionals (2019). Roadblocks to opportunity: barriers to work and employment." COM18WHT_Barriers_Whitepaper[5].pdf, 2019. Retreived from: http//www. expresspros.com

Flora, C. B., Flora, J.L.\& Gasteyer, S. P.(2018).Rural communities: legacy and change. $5^{\text {th }}$ Edition. New York: Routledge.

Khazan, O. (2017). The early deaths of Appalachians. The Atlantic 2017 (7 August).

Retreived from: https://www.theatlantic.com/health/archive/2017/08/the-early-deaths-of-appalachians/536031/

King, J. \& Waghorn, G. (2018). How higher performing employment specialists engage and support job-seekers with psychiatric disabilities. Journal of Rehabilitation, 84 (2): 48-56.

Leung, S. (2011). A Comparison of Psychometric Properties and Normality In 4-, 5-, 6-, and 11-point Likert Scales. Journal of Social Science Research, 37(4): 412-421.

Liu, S.; Huang, J. L.; Wang, M. (2014). "Effectiveness of job search interventions: A Metanalytic Review." Psychological Bulletin, 140 (4): 1009-1041. Accessed on August 30, 2019 at: https://doi.org/10.1037/a0035923

Maciag, Mike. (2018). Suicide rate highest in decades but worst in rural America. Governing the States and Localities. February $7^{\text {th }}$. Retreived from: https://www.governing.com/topics/health-human-services/gov-suicide-ratedeaths- census-rural.html

McGee, A. D. (2015). How the perception of control influences unemployed job search. ILR Review, 68(1): 184-21. https://doi.org/10.1177/0019793914556245

Melloy, R. C.; Liu, S.; Grandey, A. A. \& Shi, J (2018). Overcoming emotional and attentional obstacles: A dynamic multi-level model of goal maintenance for job seekers." Journal of VocationalBehavior,108 (October):92107.https://doi.org/10.1016/j.jvb.2018.06.009

O’Brien, D. J., Phillips, J. L., Patsiorkovsky, V. V. (2005). Linking indigenous bonding and bridging social capital. Regional Studies, 39 (8): 1041-1051.

Office of Management and Budget (OMB). (2018). Missouri demographics information. Retreived from: https://oa.mo.gov/budget-planning/demographic-information

Schneiberg, M., King, M. \& Smith, T. (2008). Social movements and organizational form: Cooperative alternatives to corporations in the American insurance, dairy and grain industries." American Sociological Review: 73(4), 635-667.

Selznick, Philip. 2011. The TVA and the grassroots: A study of politics and organization. New Orleans: Quid Pro Books. Originally published by the University of California Press in 1949.

Tisch, A. (2015). The employability of older job-seekers: Evidence from Germany. Journal of the Economics of Aging, 6:102-112.https://doi.org/10.1016/j.jeoa.2014.07.001

University of Missouri Extension. (2018). Missouri population and employment composite indicator." Retreived from: https://extension2.missouri.edu/programs/exceed-community-economic-and-entrepreneurial-development

\section{Endnote}

${ }^{1}$ This decision was supported by a comparison of Chronbach's alpha test of reliability of the three factors identified in the factor analysis, which is shown below in Table 4 . Using a 5-point scale produced an alpha reliability of 0.38 for the three factors, while a scale composed of the 3 factors using the 4 -point scale increased the alpha reliability to .787 . The effects of a neutral point - on a five-point scale - result in the dilution of the effects of neighboring categories. Thus, the elimination of neutral point - i.e., the four-point scale produces a clearer picture of the items that comprise the three factors (Leung, 2011). 